\title{
Absence of phase transformation at low temperature in Co-doped $\mathrm{LiMn}_{2} \mathrm{O}_{4}$ samples
}

\author{
Chih-Hung Shen, ${ }^{a}$ Ravi Gundakaram, ${ }^{a}$ Ru-Shi Liu ${ }^{* a}$ and Hwo-Shuenn Sheu ${ }^{b}$ \\ ${ }^{a}$ Department of Chemistry, National Taiwan University, Taipei, Taiwan, Republic of China. \\ E-mail: rsliu@ccms.ntu.edu.tw; Fax: 886-2-23636359 \\ ${ }^{b}$ Synchrotron Radiation Research Center, Hsinchu, Taiwan, Republic of China
}

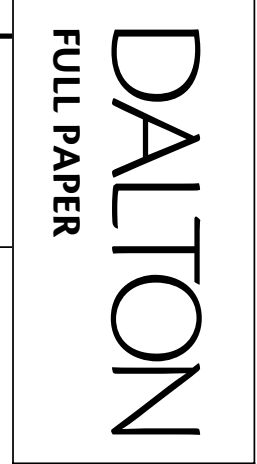

\author{
Received 4th September 2000, Accepted 17th October 2000 \\ First published as an Advance Article on the web 7th December 2000
}

\begin{abstract}
The phase transition in spinel $\mathrm{LiMn}_{2} \mathrm{O}_{4}$ was investigated using powder synchrotron radiation diffraction. A transition from cubic $(F d 3 m)$ to orthorhombic $(F d d d)$ was observed around $T=220 \mathrm{~K}$. Increasing the average valence of $\mathrm{Mn}$ by doping Co into the $\left[\mathrm{Mn}_{2} \mathrm{O}_{4}\right]$ framework, $\mathrm{LiMn}_{1.9} \mathrm{Co}_{0.1} \mathrm{O}_{4}$, reduced the concentration of $\mathrm{Mn}^{3+}$ ions, suppressed the Jahn-Teller distortion and the cubic phase was retained at low temperature.
\end{abstract}

\section{Introduction}

Lithium transition-metal ( $\mathrm{Co}, \mathrm{Ni}, \mathrm{Mn}$ or $\mathrm{V})$ oxides which are used as positive electrodes in secondary lithium batteries have extensively been studied over the past two decades. Amongst these materials, manganese oxides were found to be advantageous in terms of specific energy, non-toxicity and low cost. Lithium spinel $\mathrm{LiMn}_{2} \mathrm{O}_{4}$ is the most promising candidate for innovative lithium-ion (rocking chair) batteries. It is believed that lithium manganese oxides batteries will be used in cellular telephones, notebook PCs and electrical vehicles in the future. ${ }^{1-4}$

Some problems for the commercial application of $\mathrm{LiMn}_{2} \mathrm{O}_{4}$ are rechargeable capacity and poor cyclability of the chargedischarge process in the region of $4 \mathrm{~V}$. These could be due to lattice instability of $\mathrm{LiMn}_{2} \mathrm{O}_{4}$ with the critical concentration of $\mathrm{Mn}^{3+}$ ions. $\mathrm{LiMn}_{2} \mathrm{O}_{4}$ shows cubic $\mathrm{Fd} 3 m$ symmetry at room temperature with an average manganese valence of 3.5. The $\mathrm{Mn}$ exists in $\mathrm{Mn}^{4+}\left(\mathrm{t}_{2 \mathrm{~g}}{ }^{3} \mathrm{e}_{\mathrm{g}}{ }^{0}\right)$ and Jahn-Teller active $\mathrm{Mn}^{3+}\left(\mathrm{t}_{2 \mathrm{~g}} \mathrm{e}_{\mathrm{g}}{ }^{1}\right)$ configurations. Decreasing the temperature causes a structural phase transition around $280 \mathrm{~K}$ due to the Jahn-Teller distortion in the $\mathrm{Mn}^{3+} \mathrm{O}_{6}$ octahedra and the crystal structure of $\mathrm{LiMn}_{2}-$ $\mathrm{O}_{4}$ changes from cubic $(\mathrm{Fd} 3 \mathrm{~m})$ to tetragonal (space group; $I 4_{1} /$ amd $) .{ }^{5-9}$ Oikawa et al. ${ }^{10}$ showed that the reflections of the low temperature (LT) phase in its neutron and X-ray diffraction patterns were indexed not on the basis of a tetragonal unit cell but roughly on an orthorhombic one (space group; Fddd) with lattice parameters $a=8.2797(2), b=8.2444(3)$ and $c=$ $8.1981(2) \AA$. Therefore, the diffraction pattern of the orthorhombic phase is very similar to their LT X-ray diffraction pattern. More recently, many studies have demonstrated that $\mathrm{LiMn}_{2} \mathrm{O}_{4}$ has the orthorhombic phase at low temperature. ${ }^{11-14}$ Rodriguez-Carvajal et al. ${ }^{11}$ on the basis of neutron and electron diffraction studies proposed an orthorhombic supercell with space group $F d d d$ and $\approx 3 \times 3 \times 1$ axes with respect to the cubic value.

Several studies have been aimed at improving the material properties of $\mathrm{LiMn}_{2} \mathrm{O}_{4}$ and its efficiency in maintaining electrochemical capacity, over a large number of cycles without sacrificing initial reversible capacity, and also its performance at low or high temperatures. Doping the Mn (16d) sites with a lower valent cation is a possibility because it reduces the $\mathrm{Mn}^{3+}$ content and stabilizes the cubic structure in the face of $\mathrm{Mn}^{3+}$ Jahn-Teller distortion. ${ }^{15,16}$ Yamada $^{8}$ has shown that the substitution of $\mathrm{Li}^{+}$ions at the $\mathrm{Mn}$ site, $\mathrm{Li}\left(\mathrm{Li}_{x} \mathrm{Mn}_{2-x}\right) \mathrm{O}_{4}$, increases the average ionic valence of $\mathrm{Mn}$, thus decreasing the number of Jahn-Teller $\mathrm{Mn}^{3+}$ ions. When $x>0.035$ the phase transition near room temperature was not observed.

Towards practical applications, it is desirable to have a composition which has no structural transition close to room temperature. In this paper we report the synthesis of $\mathrm{LiMn}_{2-x^{-}}$ $\mathrm{Co}_{x} \mathrm{O}_{4}(x=0$ or 0.1$)$, wherein $\mathrm{Mn}$ has partially been replaced with Co. We also present our studies on the effect of temperature on the phase transition in $\mathrm{LiMn}_{2} \mathrm{O}_{4}$ and $\mathrm{LiMn}_{1.9} \mathrm{Co}_{0.1} \mathrm{O}_{4}$.

\section{Experimental}

Samples of the system $\mathrm{LiMn}_{2-x} \mathrm{Co}_{x} \mathrm{O}_{4}$ with $x=0$ or 0.1 were synthesized by solid-state reaction of $\mathrm{Li}_{2} \mathrm{CO}_{3}, \mathrm{MnO}_{2}$ and $\mathrm{Co}_{3} \mathrm{O}_{4}$. Well ground mixtures of the starting materials were heated at $800^{\circ} \mathrm{C}$ in air for $24 \mathrm{~h}$, followed by two treatments each of $24 \mathrm{~h}$ at $800^{\circ} \mathrm{C}$ with intermediate grindings. Powder X-ray diffraction analyses were carried out with a SCINTAG (X1) diffractometer $(\mathrm{Cu}-\mathrm{K} \alpha$ radiation, $\lambda=1.5406 \AA)$ at $40 \mathrm{keV}$ and $30 \mathrm{~mA}$. Data for the Rietveld refinement were collected in the $2 \theta$ range $15-120^{\circ}$ with a step size of $0.02^{\circ}$ and a count time of $10 \mathrm{~s}$ per step. The program GSAS ${ }^{17}$ was used for the Rietveld refinement in order to obtain the crystal structure parameters of $\mathrm{LiMn}_{2-x} \mathrm{Co}_{x} \mathrm{O}_{4}$. Compositional analyses were performed by using an EDAX-DX4 energy dispersive X-ray spectrometer (EDS).

A series of patterns was recorded with synchrotron radiation $(\lambda=1.3271 \AA)$ in a limited angular region at different temperatures. The Wiggler-A beamline of the synchrotron radiation research center (SRRC), Taiwan, has been designed for such experiments, where the concern is more with photon flux than resolution. The optical design follows a first mirror focusing the beam vertically and an asymmetrically cut and horizontally bendable perfect single crystal as the diffractive object monochromatizing and focusing the beam horizontally. The focusing mirror is an $800 \mathrm{~mm}$ long tangential bent and water-cooled silicon mirror with gold coating on the surface. A single crystal of $\mathrm{Si}(111)$ with about $10^{\circ}$ asymmetric cutting was used to deliver the monochromatic beam. The optics is designed to focus the beam into a $0.2 \times 1.8 \mathrm{~mm}$ spot size at the sample position, which is about 24 meters away from the source or 6 meters from the monochromator. The wavelength of the beam is $1.3271 \AA$. The Wiggler-A hutch is equipped with a conventional Huber 4-circle diffractometer operating in the vertical geometry to obtain the best angular resolution in the 
Table 1 Refined fractional atomic positions, unit cell and reliability factors $(\%)$ of $\mathrm{LiMn}_{2-x} \mathrm{Co}_{x} \mathrm{O}_{4}(x=0$ or 0.1$)$ having $F d 3 m$ space group at room temperature. The atomic positions are, $\mathrm{Li}(0.125,0.125,0.125), \mathrm{Mn}(0.5,0.5,0.5), \mathrm{O}(x, x, x)$

\begin{tabular}{|c|c|c|c|c|c|c|c|c|c|c|c|}
\hline$x$ & $\begin{array}{l}\operatorname{Li} 10^{2} \\
U_{\text {iso }} / \AA^{2}\end{array}$ & $\begin{array}{l}\operatorname{Mn}(\mathrm{Co}) \\
10^{2} U_{\text {iso }} / \AA^{2}\end{array}$ & $O x$ & $\begin{array}{l}10^{2} \\
U_{\text {iso }} / \AA^{2}\end{array}$ & $a / \AA ̊$ & $V / \AA^{3}$ & $\begin{array}{l}R_{\mathrm{p}} \\
(\%)\end{array}$ & $\begin{array}{l}R_{\mathrm{wp}} \\
(\%)\end{array}$ & $\chi^{2}$ & $\begin{array}{l}\text { Mn-Mn } \\
(\times 6) / \AA\end{array}$ & $\mathrm{O}-\mathrm{Li}-\mathrm{O} /{ }^{\circ}$ \\
\hline 0 & $3.3(6)$ & $2.35(3)$ & $0.2639(2)$ & $3.81(7)$ & $8.2422(2)$ & $559.93(2)$ & 9.74 & 12.89 & 1.075 & $2.91406(4)$ & $109.471(2)$ \\
\hline 0.1 & $4.0(5)$ & $2.02(3)$ & $0.2623(2)$ & $3.7(1)$ & $8.2336(2)$ & $558.17(3)$ & 8.99 & 12.18 & 1.316 & $2.91101(5)$ & $109.471(1)$ \\
\hline
\end{tabular}

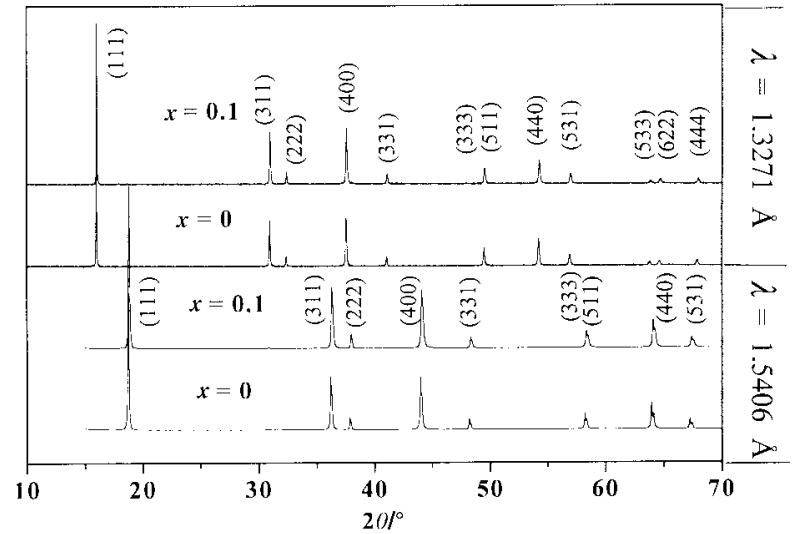

Fig. 1 Conventional ( $\mathrm{Cu}-\mathrm{K} \alpha$ radiation, $\lambda=1.5406 \AA$ ) and synchrotron $\left(\lambda=1.3271 \AA\right.$ ) powder XRD spectra of $\mathrm{LiMn}_{2-x} \mathrm{Co}_{x} \mathrm{O}_{4}$ with $x=0$ or 0.1 at room temperature.

vertical plane. Two sets of $\mathrm{X}-\mathrm{Z}$ translation slits are positioned in front of the diffractometer to define the incident angular divergences in the vertical and horizontal directions. A $5 \mathrm{~cm}$ long ionic chamber is used to monitor the incident photon flux before the slits and a scintillation counter is positioned vertically in the direction of the beam right after the slits to monitor the transported beam by counting the air scattered photons. Right in front of the detector, another scintillation counter, are two sets of $\mathrm{X}-\mathrm{Z}$ slits providing better receiving angular resolution and which also serve an as air scattering rejector.

A flat imaging plate (Fuji, $20 \times 40 \mathrm{~cm}$ ) was used as a 2-D area detector, which can collect diffraction data up to 80 degrees in $2 \theta$. The diffraction pattern is read out by using a MAC IPR420 off line imaging plate scanner. The dynamic range is as high as $10^{6}$. In this study, the sample was cooled by an APD cryostat; the temperature can be varied from 320 to $15 \mathrm{~K}$.

The valence of $\mathrm{Mn}$ was determined by chemical titration. The samples were dissolved in an excess of $20 \mathrm{~mL} \mathrm{~K}_{2} \mathrm{C}_{2} \mathrm{O}_{4}$ and $2 \mathrm{~mL} \mathrm{H}_{2} \mathrm{SO}_{4}$ at around $65^{\circ} \mathrm{C}$ maintained by a water bath to reduce all $\mathrm{Mn}^{n+}$ to $\mathrm{Mn}^{2+}(2<n \leq 4)$, and then the excess of $\mathrm{C}_{2} \mathrm{O}_{4}{ }^{2-}$ ions in the solution was determined by titration at $65^{\circ} \mathrm{C}$ with a standard solution of $\mathrm{KMnO}_{4}{ }^{18}$

\section{Results and discussion}

The conventional $(\lambda=1.5406 \AA)$ and synchrotron $(\lambda=1.3271 \AA)$ powder XRD patterns of $\mathrm{LiMn}_{2}{ }_{x} \mathrm{Co}_{x} \mathrm{O}_{4}$ with $x=0$ or 0.1 are shown in Fig. 1. Both compositions are of single phase. EDS measurements have shown that the ratio of $\mathrm{Mn}$ to Co in the composition with $x=0.1$ is $95: 5$ which is consistent with the nominal composition. The peaks in each diffraction pattern can be indexed on the basis of a cubic unit cell (space group: $F d 3 m$ ). The cell symmetry perovskite was identified by observation of the reflections with the limiting condition on $h k l: h$, $k, l$ either all odd or all even, with $F$ centering of the unit cell which is consistent with the results of the XRD pattern shown in Fig. 1. The observed and calculated diffraction profiles of the sample with $x=0.1$ using conventional X-ray diffraction are shown in Fig. 2. The ideal crystal structure of $\mathrm{LiMn}_{2-x} \mathrm{Co}_{x} \mathrm{O}_{4}$ with a cubic cell at room temperature is shown in the inset. The

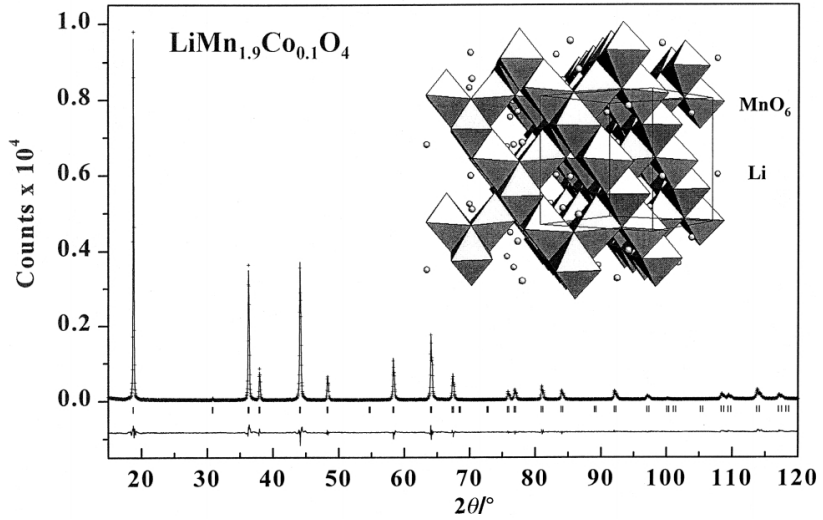

Fig. 2 Rietveld plot of $\mathrm{LiMn}_{2-x} \mathrm{Co}_{x} \mathrm{O}_{4}$ with $x=0.1$ at $300 \mathrm{~K}$. The experimental data points are shown as plus $(+)$ signs. The solid line is the calculated profile. The tick marks below the profile indicate the positions of allowed Bragg reflections. The difference plot (observed minus calculated) is shown at the bottom. The ideal crystal structure of $\mathrm{LiMn}_{2-x} \mathrm{Co}_{x} \mathrm{O}_{4}$ with cubic cell (space group: $F d 3 m$ ) shown in the inset with the unit cell as a solid line. Part of the $\mathrm{MnO}_{6}$ octahedra is shaded.

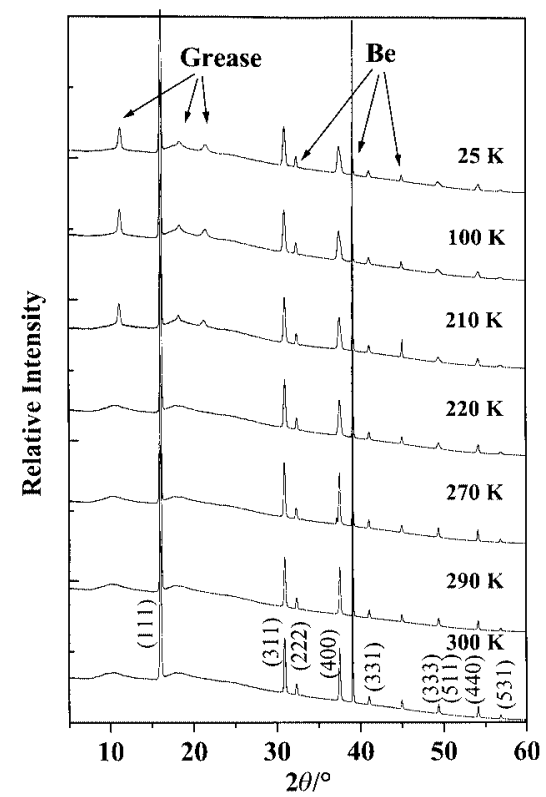

Fig. 3 Powder X-ray diffraction patterns of $\mathrm{LiMn}_{2} \mathrm{O}_{4}$, taken between 300 and $25 \mathrm{~K}$ with synchrotron wavelength $1.3271 \AA$ A. Small diffraction peaks are due to grease and the beryllium sample holder.

structural parameters of the $\mathrm{LiMn}_{2-x} \mathrm{Co}_{x} \mathrm{O}_{4}$ compositions at room temperature are listed in Table 1. The lattice constant $a$ and $\mathrm{Mn}-\mathrm{Mn}$ bond distances decrease with the addition of $\mathrm{Co}$, which is due to the smaller size of the substituting $\mathrm{Co}^{3+}$ ion $[0.61 \AA$ for C.N. (coordination number) $=6$, in low field] as compared to the larger $\mathrm{Mn}^{3+}$ ions $(0.645 \AA$ for C.N. $=6$, in low field). ${ }^{19}$

The low temperature structure of $\mathrm{LiMn}_{2} \mathrm{O}_{4}$ was investigated by powder synchrotron diffraction. The data were collected using an image plate from $300 \mathrm{~K}$ to low temperatures. Fig. 3 shows the synchrotron powder diffraction profiles recorded from 300 to $25 \mathrm{~K}$. Peak-broadening is clearly seen in the pattern 
Table 2 Comparison of calculated and observed peak positions for the space groups $F d 3 m$ and $F d d d$ of $\mathrm{LiMn}_{2} \mathrm{O}_{4}$ with synchrotron wavelength $1.3271 \AA$

\begin{tabular}{|c|c|c|c|c|c|}
\hline \multicolumn{3}{|l|}{$F d 3 m$} & \multicolumn{3}{|l|}{$F d d d$} \\
\hline$(h k l)$ & $2 \theta_{\text {calc }}{ }^{\circ}$ & $2 \theta_{\text {obs }}{ }^{a} /^{\circ}$ & $(h k l)$ & $2 \theta_{\text {calc }}^{b}{ }^{\circ}$ & $2 \theta_{\mathrm{obs}}{ }^{c}{ }^{\circ}$ \\
\hline (111) & 16.03 & 16.04 & (111) & 16.03 & 16.04 \\
\hline \multirow{3}{*}{ (311) } & 30.97 & 31.00 & (311) & 30.87 & 31.00 \\
\hline & & & (131) & 30.97 & 31.00 \\
\hline & & & (113) & 31.10 & 31.00 \\
\hline$(222)$ & 32.39 & 32.41 & $(222)$ & 32.39 & 32.41 \\
\hline \multirow[t]{3}{*}{ (400) } & 37.57 & 37.61 & (400) & 37.39 & 37.61 \\
\hline & & & $(040)$ & 37.56 & 37.61 \\
\hline & & & (004) & 37.78 & 37.77 \\
\hline \multirow[t]{3}{*}{ (331) } & 41.09 & 41.14 & (331) & 41.00 & 41.14 \\
\hline & & & (313) & 41.10 & 41.14 \\
\hline & & & (133) & 41.18 & 41.14 \\
\hline (333) & 49.46 & 49.51 & (151) & 49.45 & 49.51 \\
\hline (511) & 49.46 & 49.51 & (333) & 49.47 & 49.68 \\
\hline \multirow[t]{2}{*}{$(440)$} & 54.18 & 54.23 & (440) & 54.04 & 54.02 \\
\hline & & & (404) & 54.21 & 54.23 \\
\hline \multirow[t]{4}{*}{ (531) } & 56.89 & 56.96 & (531) & 56.69 & 56.96 \\
\hline & & & (513) & 56.77 & 56.96 \\
\hline & & & (351) & 56.81 & 56.96 \\
\hline & & & (153) & 56.95 & 56.96 \\
\hline
\end{tabular}

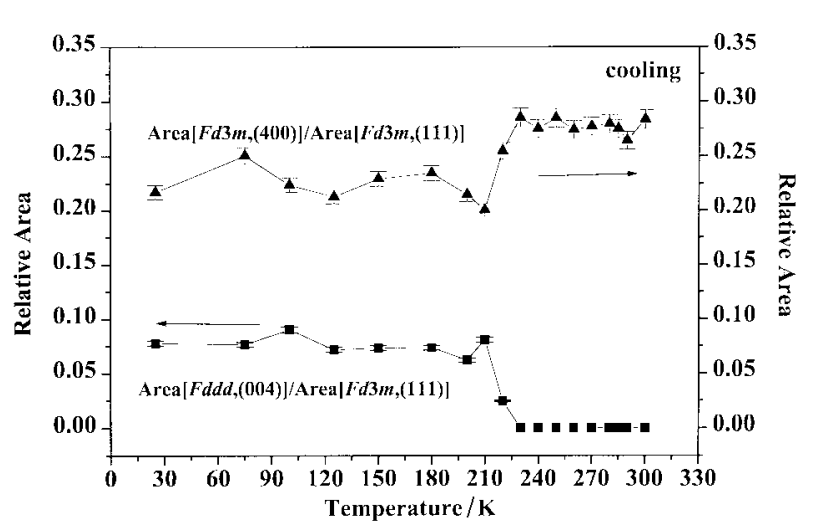

Fig. 4 Relative area as a function of temperature in $\mathrm{LiMn}_{2} \mathrm{O}_{4}$.

at $220 \mathrm{~K}$, especially for the peaks at high angles. The peaks at $11.17,18.35$, and $21.53^{\circ}$ in $2 \theta$ are from grease (used to mount the sample on to the holder) and those at 33.13, 39.28 and $45.07^{\circ}$ are from the beryllium sample holder.

$F d d d$ is a maximal non-isomorphic subgroup of $I 4_{1} /$ amd and derived from $F d 3 m$ by loss of all threefold rotation axes and part of the twofold screw axes. Wyckoff positions in the cubic spinel type structure, i.e. $8 a(1 / 8,1 / 8,1 / 8), 16 d(1 / 2,1 / 2,1 / 2)$ and $32 e(x, x, x)$ sites in $F d 3 m$, can be generated with symmetry operations in $F d d d$. In $F d d d$ the corresponding Wyckoff positions are $8 a(1 / 8,1 / 8,1 / 8), 16 d(1 / 2,1 / 2,1 / 2)$ and $32 h(x, y, z) .^{10}$ In Table 2 a comparison of the observed and calculated peaks for the space groups $F d 3 m$ and $F d d d$ is presented. The lattice constants are $a=8.242 \AA$ for the cubic phase and $a=8.2797(2)$, $b=8.2444$ (3) and $c=8.1981$ (2) $\AA$ for the orthorhombic phase, ${ }^{10}$ which have been calculated using the $2 \theta$ and $(h k l)$ values obtained from the XRD patterns. The parameters of the orthorhombic structure also having the same limiting condition on the $h, k, l$ as that of the cubic structure can be seen in Table 2 . In Fig. 4 we show the temperature dependence of the relative area of the (400) peak indexed by the space group $F d 3 m$ and the (004) peak indexed by $F d d d$ for the $\mathrm{LiMn}_{2} \mathrm{O}_{4}$ sample. On cooling, the transformation to orthorhombic $\mathrm{LiMn}_{2} \mathrm{O}_{4}$ begins at $220 \mathrm{~K}$ and is complete at $210 \mathrm{~K}$. Yamada ${ }^{8}$ has presented the DSC curve for $\mathrm{Li}\left(\mathrm{Li}_{x} \mathrm{Mn}_{2-x}\right) \mathrm{O}_{4}(0<x<0.04)$ in the temperature range 150 to $350 \mathrm{~K}$ and shown that the phase transition temperature is very sensitive to $\mathrm{Li}^{+}$cation

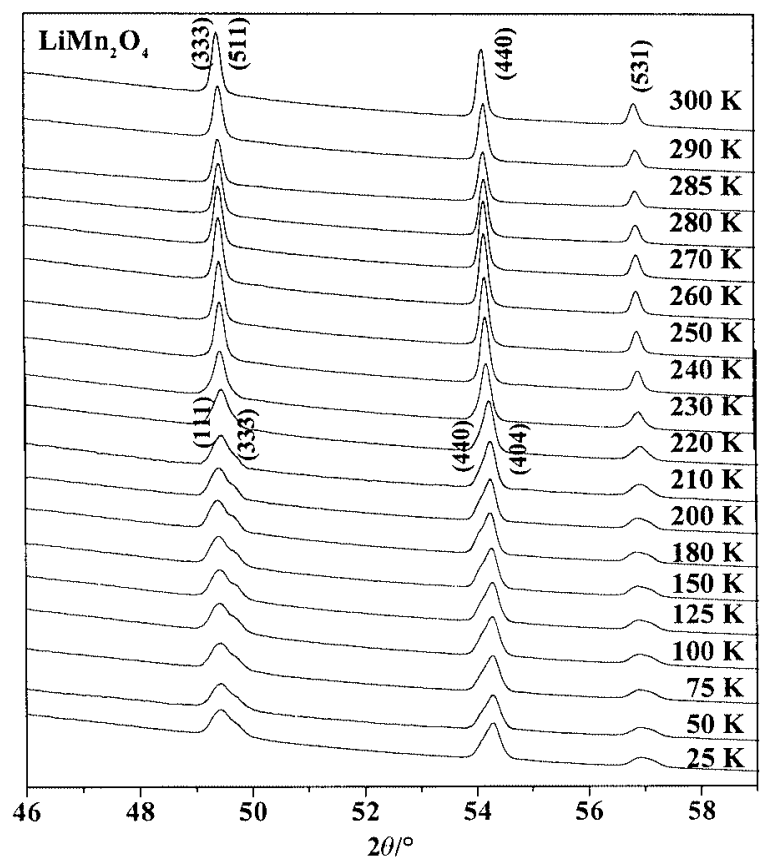

Fig. 5 Powder X-ray diffraction patterns of $\mathrm{LiMn}_{2} \mathrm{O}_{4}$ at $2 \theta$ in the $46-59^{\circ}$ region, taken between 300 and $25 \mathrm{~K}$ with synchrotron wavelength $1.3271 \AA$.

non-stoichiometry $x$. It drastically decreased from 282.3 to $214.3 \mathrm{~K}$ when a small amount of $\mathrm{Mn}$ was replaced by $\mathrm{Li}^{+}$ $(0<x<0.033){ }^{8}$ In our case the temperature of the structural transition shifts to $220 \mathrm{~K}$ which means that chemical substitution of manganese sites by the smaller $\mathrm{Li}^{+}(x \leq 0.026)$ has taken place. The formula for our composition can be written as $\mathrm{Li}\left(\mathrm{Li}_{0.026} \mathrm{Mn}_{1.974}\right) \mathrm{O}_{4}$. The $\mathrm{Li}$ substituting the $\mathrm{Mn}$ increases the valence of the manganese and only by changing the ratio of $\mathrm{Li}$ and $\mathrm{Mn}$ in the structure the valence of $\mathrm{Mn}$ changes in the $\mathrm{Li}\left(\mathrm{Li}_{x} \mathrm{Mn}_{2-x}\right) \mathrm{O}_{4}$ compositions. By chemical titration, we have determined the valence of $\mathrm{Mn}$ of the $\mathrm{LiMn}_{2} \mathrm{O}_{4}$ sample to be $3.505 \pm 0.004$. The present results for increased manganese valences in our compound strongly suggest that a small amount of $\mathrm{Li}$ substitutes for $\mathrm{Mn}$ at the octahedral site and that the value of $x$ is less than 0.026 .

Fig. 5 shows the diffraction patterns of $\mathrm{LiMn}_{2} \mathrm{O}_{4}$ in the $46-59^{\circ}(2 \theta)$ range at different temperatures from 300 to $25 \mathrm{~K}$. With decreasing temperature, narrowing of the peaks is expected. However, the peaks become broader, as can be seen. From the patterns shown the (333) and (511) reflections around $2 \theta$ of $49.51^{\circ}$ with the $F d 3 m$ cubic spinel split into (111) and (333) reflections of the orthorhombic Fddd phase below $220 \mathrm{~K}$. The (440) reflection at $54.23^{\circ}$ splits into (440) and (404) reflections. The broadening of the (531) peak at $2 \theta 56.96^{\circ}$ below $220 \mathrm{~K}$ is due to its splitting into four closely spaced reflections (531), (513), (351) and (153) as can be seen from Table 2. Yamaguchi et al. ${ }^{5}$ have used X-ray absorption spectroscopy of the manganese $\mathrm{K}$ edge to investigate the valence state and local structure of $\mathrm{LiMn}_{2} \mathrm{O}_{4}$ at $280 \mathrm{~K}$. The local structure was analyzed using isotropic $\mathrm{Mn}^{4+} \mathrm{O}_{6}$ and anisotropic $\mathrm{Mn}^{3+} \mathrm{O}_{6}$ octahedra in $\mathrm{LiMn}^{3+} \mathrm{Mn}^{4+} \mathrm{O}_{4}$. The structure exhibits local ordering of the distorted $\mathrm{Mn}^{3+} \mathrm{O}_{6}$ octahedra when the temperature is below the transition temperature. The macroscopic distortion appears by ordering the local Jahn-Teller distortion below the transition temperature of $220 \mathrm{~K}^{5}$ Consequently, in the cubic phase above the transition temperature, the $\mathrm{Mn}^{3+} \mathrm{O}_{6}$ octahedra are distorted by the Jahn-Teller effect, which is a local distortion without static or dynamic order. Therefore, the charge ordering process is accompanied by the presence of an orbital ordering which is a manifestation of the Jahn-Teller polaronic nature of the mobile charge above and below the transition temperature. ${ }^{11}$ 


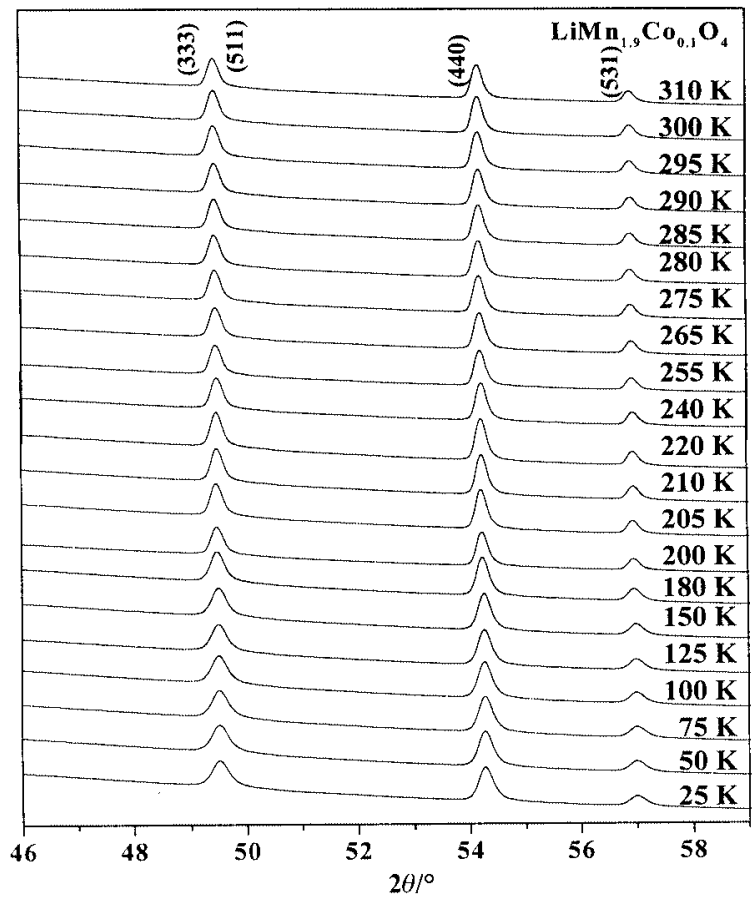

Fig. 6 Powder X-ray diffraction patterns of $\mathrm{LiMn}_{1.9} \mathrm{Co}_{0.1} \mathrm{O}_{4}$ at $2 \theta$ $46-59^{\circ}$, taken between 300 and $25 \mathrm{~K}$ with synchrotron wavelength $1.3271 \AA$ A.

The chemical substitution of $\mathrm{Co}^{3+}$ for $\mathrm{Mn}^{3+}$ in $\mathrm{LiMn}_{2} \mathrm{O}_{4}$ increases the valence of $\mathrm{Mn}$. The valence in $\mathrm{LiMn}_{1.9} \mathrm{Co}_{0.1}{ }^{-}$ $\mathrm{O}_{4}$, as determined by chemical titration, is $3.526 \pm 0.006$. Therefore, the $\mathrm{LiMn}_{1.9} \mathrm{Co}_{0.1} \mathrm{O}_{4}$ composition can be written as $\mathrm{Li}\left(\mathrm{Co}^{3+}{ }_{0.1} \mathrm{Mn}^{3+}{ }_{0.9} \mathrm{Mn}^{4+}{ }_{1.0}\right) \mathrm{O}_{4}$. Shimakawa et $a l .{ }^{6}$ have reported that in $\mathrm{Li}\left(\mathrm{Li}^{+}{ }_{0.033} \mathrm{Mn}^{3+}{ }_{0.901} \mathrm{Mn}^{4+}{ }_{1.066}\right) \mathrm{O}_{4}$ and $\mathrm{Li}\left(\mathrm{Li}^{+}{ }_{0.066} \mathrm{Mn}^{3+}{ }_{0.806}\right.$ $\left.\mathrm{Mn}^{4+}{ }_{1.129}\right) \mathrm{O}_{4}$, the average manganese valence is greater than $3.5+$ and the amount of the Jahn-Teller $\mathrm{Mn}^{3+}$ ions is less than $50 \%$. The samples with increased $\mathrm{Li}$ at the manganese site showed no anomalous change in resistivity and susceptibility. Yamada ${ }^{8}$ has observed that the DSC peaks corresponding to the phase transition were smeared out in $\mathrm{Li}_{\left(\mathrm{Li}^{+}\right.}{ }_{0.035}$ $\left.\mathrm{Mn}^{3+}{ }_{0.895} \mathrm{Mn}^{4+}{ }_{1.07}\right) \mathrm{O}_{4}$. Fig. 6 shows the synchrotron diffraction patterns of a $\mathrm{LiMn}_{1.9} \mathrm{Co}_{0.1} \mathrm{O}_{4}$ sample showing the cubic spinel peaks (333), (511), (440), and (531) in the $2 \theta$ range of $46-59^{\circ}$ from 300 down to $25 \mathrm{~K}$. As can be seen, there is no peak split or broadening from room to low temperature. Masquelier et al. ${ }^{7}$ have also reported that in the X-ray diffraction patterns of $\mathrm{Li}_{1.01} \mathrm{Mn}^{3+}{ }_{0.76} \mathrm{Mn}^{4+}{ }_{1.18} \mathrm{O}_{4}$, no peak splitting could be detected at 323,298 , and $103 \mathrm{~K}$. In $\mathrm{Li}_{1.01} \mathrm{Mn}^{3+}{ }_{0.76} \mathrm{Mn}^{4+}{ }_{1.18} \mathrm{O}_{4}$ the $\mathrm{Mn}^{3+}$ content is reduced from $50 \%$ (as in $\mathrm{LiMn}_{2} \mathrm{O}_{4}$ ) to $38 \%$ per octahedral $(16 d)$ site in the $\left[\mathrm{Mn}_{2} \mathrm{O}_{4}\right]$ spinel framework, which is sufficient to suppress the distortion at $103 \mathrm{~K}$. The substitution effect of $\mathrm{Co}^{3+}$ on the framework would be local in the $16 d$ site, which is similar to an excess of $\mathrm{Li}^{+}$being substituted into the manganese site. In $\mathrm{LiMn}_{1.9} \mathrm{Co}_{0.1} \mathrm{O}_{4}$ the $\mathrm{Mn}^{3+}$ content decreases to $47 \%$, thus bringing about a change in the magnetic ordering. As we can see, the $\mathrm{Mn}^{3+} \mathrm{Jahn}-$ Teller distortion is small in $\mathrm{LiMn}_{1.9} \mathrm{Co}_{0.1} \mathrm{O}_{4}$ at room temperature. However, at low temperature, the ordering of the distorted $\mathrm{Mn}^{3+} \mathrm{O}_{6}$ octahedra is quite small in $\mathrm{LiMn}_{1.9} \mathrm{Co}_{0.1} \mathrm{O}_{4}$ as compared to the composition with $\mathrm{LiMn}_{2} \mathrm{O}_{4}$

In conclusion, we have carried out conventional and synchrotron powder X-ray diffraction studies of $\mathrm{LiMn}_{2}{ }_{x} \mathrm{Co}_{x} \mathrm{O}_{4}$ with $x=0$ and $0.1 . \mathrm{LiMn}_{2} \mathrm{O}_{4}$ shows a phase transition at $220 \mathrm{~K}$ that is associated with cubic-orthorhombic distortion. Reduction of the concentration of the $\mathrm{Mn}^{3+}$ ions results in suppression of the Jahn-Teller distortion in $\mathrm{LiMn}_{1.9} \mathrm{Co}_{0.1} \mathrm{O}_{4}$ and the cubic phase is retained at low temperature.

\section{Acknowledgement}

This research has been supported by the National Science Council of the Republic of China under the grant number NSC 89-2113-M-002-059.

\section{References}

1 M. M. Thackeray, W. I. F. David, P. G. Bruce and J. B. Goodenough, Mater. Res. Bull., 1983, 18, 461.

2 M. M. Thackeray, P. J. Johnson, L. A. de Picciotto, P. G. Bruce and J. B. Goodenough, Mater. Res. Bull., 1984, 19, 179.

3 J. B. Goodenough, Solid State Ionics, 1994, 69, 184

4 M. M. Thackeray, J. Electrochem. Soc., 1995, 142, 2558.

5 H. Yamaguchi, A. Yamada and H. Uwe, Phys. Rev. B, 1998, 58, 8.

6 Y. Shimakawa, T. Numata and J. Tabuchi, J. Solid State Chem., 1997, 131, 138

7 C. Masquelier, M. Tabuchi, K. Ado, R. Kanno, Y. Kobayashi, Y. Maki, O. Nakamura and J. B. Goodenough, J. Solid State Chem., 1996, 123, 255

8 A. Yamada, J. Solid State Chem., 1996, 122, 160.

9 A. Yamada and M. Tanaka, Mater. Res. Bull., 1995, 30, 715.

10 K. Oikawa, T. Kamiyama, F. Izumi, B. C. Chakoumakos, H. Ikuta, M. Wakihara, J. Li and Y. Matsui, Solid State Ionics, 1998, 109, 35.

11 J. Rodriguez-Carvajal, G. Rousse, C. Masquelier and M. Hervieu, Phys. Rev. Lett., 1998, 81, 4660.

12 A. S. Wills, N. P. Raju and J. E. Greedan, Chem. Mater., 1999, 11, 1510.

13 V. Massarotti, D. Capsoni, M. Bini, P. Scardi, M. Leoni, V. Baron and H. Berg, J. Appl. Crystallogr., 1999, 32, 1186.

14 G. Rousse, C. Masquelier, J. Rodriguez-Carvajal, E. Elkaim, J.-P. Lauriat and J. L. Martinez, Chem. Mater., 1999, 11, 3629.

15 A. D. Pasquier, A. Blyr, P. Courjal, D. Larcher, G. Amatucci, B. Gerand and J.-M. Tarascon, J. Electrochem. Soc., 1999, 146, 428.

16 L. Guohua, H. Ikuta, T. Uchida and M. Wakihara, J. Electrochem. Soc., 1996, 143, 178 .

17 A. C. Larson and R. B. von Dreele, Generalized Structure Analysis System, Los Alamos National Laboratory, Los Alamos, NM, 1994.

18 M. J. Katz, R. C. Charke and W. F. Nye, Anal. Chem., 1956, 28, 507.

19 R. D. Shanon, Acta Crystallogr., Sect. A, 1976, 32, 751. 